\title{
Analysis of Environmental Benefits of Green Buildings from the Perspective of Carbon Emissions
}

\author{
Yiyu Chen ${ }^{1,2, \text { a } \text {, Lei Luo }}{ }^{3,2, b, *}$ \\ ${ }^{1}$ Anhui Jianzhu University, Hefei230022, Anhui,China \\ ${ }^{2}$ City University of Macau, Dangzai 999078 Aomen, China \\ ${ }^{3}$ Huangshan University, Huangshan245041, Anhui, China
}

\begin{abstract}
With the rapid improvement of China's socio-economic level, the importance of ecological environmental protection has become increasingly important. As a major factor affecting ecological environmental protection, carbon emissions have received high attention. At the same time, various tasks for energy conservation and emission reduction have entered a period of rapid development. In China's construction industry, green buildings are the main measures for energy conservation and emission reduction. The use of green buildings to achieve water, material, and energy conservation can not only ensure environmental benefits, but also improve ecological benefits. In order to further improve the environmental benefits of green buildings from the perspective of carbon emissions, it is also necessary to conduct a specific analysis combining the development advantages and environmental benefits of green buildings.
\end{abstract}

\section{Introduction}

The improvement of socio-economic level and the protection of ecological benefits have always been in the opposite direction. The era of improving social economy at the expense of ecological benefits has passed. In the current era, people are seeking ways and measures to simultaneously improve social economic and ecological benefits 1]. As the main factor affecting environmental benefits, carbon emissions have become the main control link in the current social development and construction. The construction industry has also paid closer attention to carbon emission control in order to save energy and reduce building energy use and carbon. The green building concept of emissions is gradually perfecting and highlighting. This perfectly adapts to the green concept and can also improve environmental benefits.

\section{Analysis of Environmental Benefits of Green Buildings from the Perspective of Carbon Emissions}

\subsection{Reduce the Environmental Impact of Building Pollution}

In the development of the construction industry, a lot of land resources are occupied, and the destruction of water and land resources and natural resources is unavoidable. This is also the conflict and contradiction in the traditional construction industry and ecological

*Corresponding Author a email: yiyu058@ahjzu.edu.cn;

bemail: luolei5257@hsu.edu.cn environment protection. From the perspective of current carbon emissions, the construction industry looks at the development of the industry with a green building concept, attaches more importance to the impact of the construction industry on environmental benefits, and improves the protection of the environment. In the construction industry in the past, there were various types of construction pollution, including dust pollution, water pollution, and air pollution during the construction process. A variety of construction pollution not only adversely affected the environment and ecology, but also caused the overall society of construction engineering Reduced ecological benefits. As a part of the people's livelihood project, the construction project should balance the ecological benefits on the basis of satisfying the social benefits. Therefore, the proposal of the green building concept has improved the ecological benefits of the construction project. In green building projects, building pollution has been reduced, and weakening effects have been achieved in a variety of pollution factors, such as reduced air pollution. And energy-saving equipment in building construction, using clean energy to reduce the use of diesel and other energy sources, thereby reducing carbon emissions and air pollution. Therefore, it can be said that under the concept of green building, construction pollution has been controlled and reduced, and the impact on the environment has been reduced, and the environmental ecological benefits have been improved. 


\subsection{Reduce Environmental Damage to Building Materials}

In the construction industry, many building materials are sourced from the environment. Timber tree species are often in short supply in the construction market, resulting in huge consumption of resources. Under the concept of green building, the use of construction materials using natural environment as a material is reduced, which not only reduces the environmental damage to the construction industry, but also improves the environmental ecological benefits of the construction industry [2]. Currently in the construction materials market, many new environmental protection equipment and materials have emerged, such as solar thermal products and renewable materials, which have provided new markets for construction materials in the construction industry, reducing the damage to the natural environment, effectively enhance the protection of natural ecology. Under the concept of green building, the simplification of building materials reduces waste of resources. For example, in the construction of external walls of buildings, the thickness of external walls is reduced by thermal insulation materials, which saves building materials and improves energy efficiency.

\subsection{Enhancing Energy-saving Attributes and Forming Environmental Protection}

From the perspective of carbon emissions, the green building concept is effectively combined with building construction projects, giving play to the advantages of green buildings, and further improving the building's green energy-saving properties. At present, in green buildings, the full application of renewable energy and clean energy has achieved energy saving effects, and improved the building's properties of heat preservation, ventilation, light transmission and heat insulation. At the same time, it can also combine green ecological resources to improve the ecological benefits of buildings. For example, green plants are cultivated around the building and on the top of the building, and photosynthesis and transpiration of green plants are used to improve the environmental advantages of the building and reduce energy usage. It can be recognized that under the current green building concept, the energy-saving properties of buildings have been continuously improved, and more attention has been paid to the green concept in terms of energy conservation and resource utilization. It also improves the ecological and environmental benefits [3].

\subsection{Green Building Saves Land Resources}

In terms of environmental benefits, it has become more common for green buildings to achieve energy conservation through energy conservation, water conservation and building materials conservation. However, land resource conservation is actually more difficult to understand, and the actual application effect of land resource conservation is also weak. In the concept of green building, the consumption of land resources is much less than that of traditional buildings, and the utilization efficiency of land resources is higher. This is because there is a good concept of land intensification in the site selection of the building, the public service facilities around the building are sound, and the effective use of land is better achieved in urban construction. At the same time, green buildings make full use of underground space, and the effective connection between ground space and underground space lays a good foundation for the intensive use of land resources [4]. From the perspective of land resources, the ecological and environmental benefits are the most easily overlooked link. The use and destruction of land resources cause the loss of ecological and environmental resources. Therefore, in the concept of green building, it is worth exploring and digging to reduce the use of land resources and achieve environmental benefits.

\section{Carbon Emission Accounting and Case Analysis for the Entire Life Cycle of Green Buildings}

In the whole life cycle project management mode of green building, from the project decision-making, project design, project construction to project operation and maintenance, the entire process management needs to be formed to ensure the good implementation of green building projects. From the perspective of the entire life cycle cost of green buildings, the cost of green buildings includes energy costs, building material costs, and building maintenance costs. Under the green building concept, building materials are mainly high-energy materials, which can reduce building maintenance costs, improve building material recycling efficiency, and meet the low-carbon energy saving concept [5].

In order to further explore the full life cycle carbon emission accounting method of green buildings, a construction example of an office building in Tianjin was used for analysis. The office building is mainly composed of ground buildings combined with underground buildings. There are five floors on the ground and one floor on the ground. The functional properties of the building are offices. The building area is $8234.57 \mathrm{~m}^{2}$, the building cold load is $583 \mathrm{kw}$, and the heat load is $350 \mathrm{kw}$. In the construction planning and project application, the building has met the requirements of the "Green Building Evaluation Standard" GB / T50378-2006. The following is an analysis of the carbon emissions accounting for the entire life cycle of this green building.

\subsection{Determination of Carbon Emission Factors}

In green building projects, the determination of carbon emission factors is the main factor in accounting for carbon emissions. The main source of carbon emissions in building construction is the transfer of fossil fuels and electricity. The fossil fuels include natural gas, liquefied petroleum gas, gasoline, diesel, kerosene, crude oil, fuel oil, and liquefied natural gas. Carbon emissions are 
generated in this type of fossil fuels and electricity. Table 1 below shows the carbon emission factors for this green building.

Table 1 Carbon Emission Factors

\begin{tabular}{|c|c|c|c|}
\hline Emission Source & Type & Unit & Emission Factor \\
\hline \multirow{4}{*}{ Fossil Fuel } & Natural Gas & tco2/m3 & 0.0021 \\
\cline { 2 - 4 } & Liquefied Petroleum Gas & Tco2/t & 3.09 \\
\cline { 2 - 4 } & Gasoline & Tco2/t & 2.91 \\
\cline { 2 - 4 } & Diesel & Tco2/t & 3.10 \\
\cline { 2 - 4 } & Kerosene & Tco2/t & 3.02 \\
\cline { 2 - 4 } & Crude & Tco2/t & 3.03 \\
\cline { 2 - 4 } & Fuel Oil & Tco2/t & 3.16 \\
\cline { 2 - 4 } & Liquified Natural Gas & Tco2/t & 2.91 \\
\hline Power Transfer in and out & Electric Power & Tco2/KWh & $1.0020 \times 10^{-3}$ \\
\hline
\end{tabular}

\subsection{Determination of other Factors}

The age of the green building is determined to be 50 years. Due to the low occupancy rate of the project, the energy loss is monitored after the use of the building, including the energy loss of heating, ventilation, air conditioning, and lighting equipment.

\subsection{Benefit Analysis of Energy Saving and Emission Reduction}

Compared with other construction projects, this green building project saves a total of $6550 \mathrm{MWh}$ during the entire life cycle of the green building. Taking the annual calculation unit, it can save 131.13MWh of energy each year. The construction project accounts for $16.60 \%$ of the total energy savings. Figure 1 below is an analysis chart of the energy saving and emission reduction benefits of this green building.

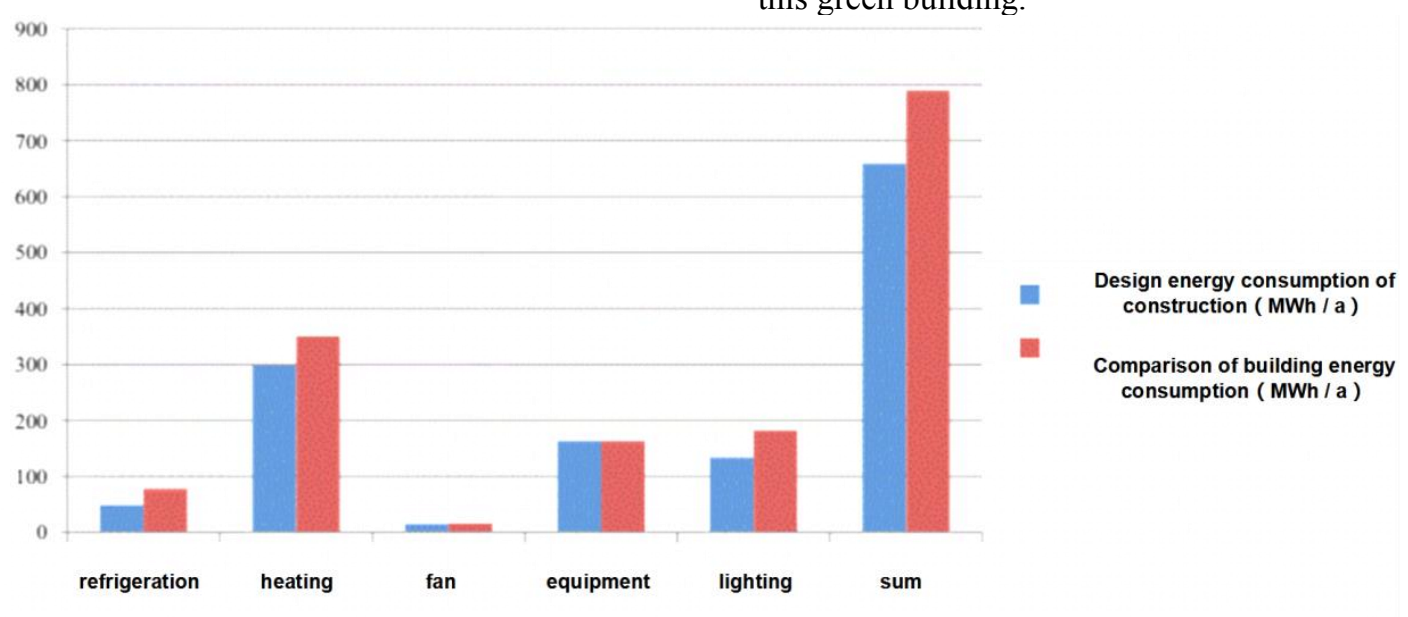

Figure 1 Benefit Analysis of Energy Saving and Emission Reduction

\subsection{Case Experience Summary}

The scientific management of green buildings in the whole life cycle is conducive to reducing the energy consumption of building construction and building investment, as well as reducing carbon emissions, which is well adapted to the modern green building concept of energy conservation and environmental protection. At the same time, the construction project is well connected with energy conservation and emission reduction, so that energy conservation and emission reduction has become the focus of the construction project. This has a practical effect on promoting the further development of construction projects and planning. It is also conducive to improving the ecological environmental benefits. Based on the above case analysis, we can know that in the entire life cycle of green buildings. We need to do a good job in carbon emissions accounting, clarify the carbon emissions accounting method, form a comprehensive survey of carbon emission factors and other influencing factors. We are supposed to clarify that carbon emissions are in the life cycle of green buildings control measures in order to reduce the carbon emissions of green buildings.

\section{Conclusion}

Carbon emissions are the main reason for destroying the ecological benefits of the environment. Under the concept of green buildings, building energy conservation and environmental protection highlight the ecological and environmental protection value of buildings. This can not only meet the energy conservation and environmental protection needs of modern society, but also achieve carbon emission control effect. From the perspective of carbon emissions, it is even more 
important to improve the environmental ecological benefits of green buildings and enhance the entire life cycle control effect of green buildings. At the same time, it can reduce building energy consumption, reduce irrational building materials, increase the environmental protection value of buildings, and better protect the ecological environment.

\section{Acknowledgements}

This work was supported by:

1.Natural science research project of colleges and universities in Anhui Province, (No: KJ2019JD06)

2.Support Project of Excellent Young Talents in Colleges and Universities of Anhui Province, (No: K1910105)

\section{References}

1. Wang Haiying, Song Xiaojun, Zhang Jingtang. Talking about the main points of mastering green building design in architectural design [J]. Jushe, 2019 (32): $100+136$

2. Wen Liang. Analysis on the integration and application of green building design concepts in house design [J]. Jushe, 2019 (32): $122+130$.

3. Wu Qunyan. Preliminary study on the integration and application of green building design concepts in building design [J]. Building Materials and Decoration, 2019 (31): 71-72.

4. Yang Cai,Wei-Wei Wang,Cheng-Wei Liu,Wen-Tao Ding,Di Liu,Fu-Yun Zhao. Performance evaluation of a thermoelectric ventilation system driven by the concentrated photovoltaic thermoelectric generators for green building operations[J]. Renewable Energy,2020,147(Pt 1).

5. Xinyu $\mathrm{Hu}$,Yongmei Wang,Liangliang Zhang,Man $\mathrm{Xu}$. Construction of self-assembled polyelectrolyte complex hydrogel based on oppositely charged polysaccharides for sustained delivery of green tea polyphenols[J]. Food Chemistry,2020,306. 